\section{Joint Commission Establishes New Department to Handle Questions About Standards Interpretation}

The Joint Commission on Accreditation of Healthcare Organizations has established a new department to handle questions about interpretation of standards and other performance measures. The core of the new Department of Performance Measure Interpretation is the former interpretations unit of the Department of Standards. The department, headed by Dr. Richard Croteau, will eventually expand its capabilities to include interpretation of indicator data.

Questions concerning the interpretation of standards and indicators for all accreditation programs should be directed to the Interpretations Callboard Operator at (708) 9165900.

\section{AIDS Patients with Drug-Sensitive TB Develop Superinfection with MDR- TB}

Clinicians at a Bronx medical facility recently reported three patients with AIDS in whom superinfection with rifampin-isoniazid-streptomycin-ethambutol (RISE)-resistant tuberculosis (TB) occurred during therapy for drug-susceptible TB. This was documented by DNA fingerprinting using the mixed-linked polymerase chain reaction technique. These patients had been exposed to other patients with RISE-resistant TB during their hospitalization.

There have been other reports of exogenous reinfection with new strains of Mycobacterium tuberculosis in AIDS patients. The waning protective immunity associated with AIDS is believed to facilitate superinfection or exogenous reinfection in patients previously treated effectively or receiving therapy for tuberculosis. The findings of this investigation support the practice of not placing more than one patient with TB in one room. Population-based studies are still needed to quantify the incidence of exogenous reinfection or super-infection to determine the extent of the risk.

FROM: Horn DL, Hewlett D, Haas WH, et al. Super-infection with rifampin-isoniazid-streptomycinethambutol-resistant TB in three patients with AIDS. Ann Intern M ed 1994;121:115-116.

\section{Possible Nosocomial Transmission of HIV to Infant}

The New York City Department of Health, in conjunction with the CDC, has reported the results of an investigation that indicates that transmission of HIV to an infant possibly occurred during hospitalization. The infant had no identified risk factors for acquisition of HIV-both parents were HIV negative and the infant never received blood or blood products, no other person in contact with the child at home was known to be HIV infected, and there was no suspicion of physical or sexual abuse.

The exact mechanism of transmission remains unknown, but the most likely opportunity for exposure to blood or body fluids containing blood was during medical procedures performed by healthcare workers caring for other children with AIDS during a hospitalization at 11 days of age for treatment of an eye infection. Extensive interviews were conducted with healthcare workers who cared for the infant and with family members and other patients who were treated on the same ward where the infant was born and where he was hospitalized. Only two HIV-positive individuals-both children-could be identified during the course of the investigation as possible sources of infection. DNA fingerprinting showed one of them to be an unlikely source of infection. HIV-DNA could not be obtained from the other HIV-infected child (Child A) because the child died prior to the investigation.

During his hospitalization at 11 days of age, the infant underwent 99 medical procedures that involved the use of needles or mucous membrane contact. During the same period, Child A underwent 79 medical procedures. On 32 occasions, medical procedures were performed on both children within a one-hour period by the same healthcare workers. Although no breaches of infection control practices could be determined, the frequency of procedures on the infant and Child A appear to offer the greatest opportunity for the infant's exposure to HIV-infected blood or body fluids.

HIV transmission has been reported in association with improper reuse of contaminated needles and syringes in Russia and Romania, and in the United States and The Netherlands during the performance of nuclear medicine procedures when blood from one patient was inadvertently injected into another patient from syringe mix-up. Possible patient-topatient transmission also was reported in a surgeon's office in Australia, which was believed to be due to a breach in infection control practices.

HIV transmission in hospital settings is extremely rare. However, the possibility of transmission of HIV during medical care underscores the need for strict adherence to infection control guidelines to prevent situations in which blood and body fluid contact is possible.

FROM: Bland S, Simonds RJ, Welsfuse I, et al. Possible nosocomial transmission of HIV. Lancet 1994;334:512-514. 


\section{SUBMISSION OF ABSTRACTS DEADLINE: J ANUARY 10, 1995}

\section{The Fifth Annual Meeting of}

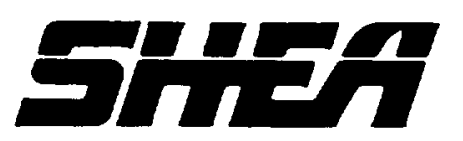

\section{The Society for Healthcare Epidemiology}

of America

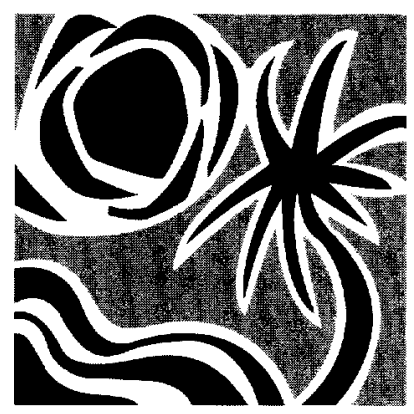

\section{APRIL 2-4, 1995 \\ THE TOWN \& COUNTRY HOTEL, SAN DIEGO, CALIFORNIA}

15.5 hours of Category I/ AMA Credit

For Preliminary Program and Registration Information, please contact SHEA at 609-845-1720 or fax 609-853-0411

The University of California, San Diego School of Medicine is accredited by the Accreditation Council for Continuing Medical Education (ACCME) to sponsor continuing medical education for physicians.

The University of California, San Diego School of Medicine designates this continuing medical education activity for 15.5 credit hours in Category 1 of the Physicians Recognition A ward of the American Medical Association, and for the certification program of the California Medical Association.

SHEA welcomes the submission of abstracts of original contributions for presentation during the Fifth Annual Meeting. Abstracts will be selected for Platform and Poster sessions based on scientific merit. To be considered, abstracts must be submitted on the official abstract form before January 10, 1995. A limited number of "Late Breaker" abstracts on recent investigations or studies of national importance will be considered if submitted before February 24, 1995.

Abstract submissions may be nominated for the SHEA Young Investigator A ward or the SHEA Trainee Award for presentation at the Annual Meeting.

For further information regarding the above awards or to obtain abstract forms, please contact SHEA Meetings Department, 875 Kings Highway, Suite 200, Woodbury, NJ 080963172 U.S.A. Tel. (609) 845-I 720; Fax (609) 853-0411. 